Conclusion* Appropriate preoperative imaging evaluation of potential anatomic variations based on imaging findings may contribute in avoiding significant intraoperative challenges.

\section{AUDIT ON COMPLIANCE IN ADHERING TO NEW IMAGING PROTOCOL IN ENDOMETRIAL CANCER}

S Ragi*, C Innes, A Campbell, S Gurram. NHS, UK

10.1136/ijgc-2021-ESG0.210

Introduction/Background* Regional guidelines were changed from MRI scan to CT scan as the choice of investigation to optimize treatment decision making in women with endometrial cancer. We audited our practice to assess the compliance in adhering to this guideline, to assess to need for further investigations like MRI and to correlate our CT staging to final histological staging.

Methodology All Endometrial cancer cases diagnosed on pippelle biopsy from Aug 2017 to Mar 2020 were retrospectively analyzed. We reviewed case notes, radiology and pathology results to assess the compliance in following the guideline and the reasons for performing additional MRI scans.

Result(s)* There were 198 cases during this period. Grade 1 Endometrioid Endometrial Cancer (EEC): 92; Grade 2 EEC:37; Grade 3 EEC :35, Serous, clear cell adenocarcinoma, or carcinosarcoma: 21; Atypical/Complex Atypical hyperplasia :11. Biopsy was inconclusive in 2 .

Our compliance in adhering to requesting CT scan was 99\% (196 out of 198 cases). In addition to CT scan MRI scan was only required in $19 \%$ of cases $(8 \%, 29 \%, 33 \%$ of patients in Gr 1 EEC, Gr 2 or 3 EEC and other types of endometrial cancer respectively). In 11 patients (5\%) CT scan was performed for additional reasons.

The reasons for imaging (CT and MRI) out with the policy were MDT request (14), pre op evaluation (9), local extension (10), Adnexal masses (5), Radiologist request (2).

In cases where CT staging and final histological staging was available $(\mathrm{N}=38)$, the Positive Predictive Value of CT scan in staging the disease in stage 1 , stage 2 and stage 3 are $100 \%$, $33 \%$ and $70 \%$ respectively.

Conclusion* Our compliance in adhering to the guideline was good and we managed to reduce the MRI work load by $80 \%$. This change in trust guidelines makes optimal use of premium resources like MRI scan.

\section{COMPARISON OF CLINICOPATHOLOGICAL CHARACTERISTICS AND SURVIVAL OUTCOMES OF PATIENTS WITH GRADE III ENDOMETRIOID ADENOCARCINOMA AND CARCINOSARCOMA}

${ }^{1} \mathrm{~K}$ Güngördük, ${ }^{2} \mathrm{H}$ Plett, ${ }^{3} \mathrm{~V}$ Gülseren, ${ }^{4} \mathrm{MM}$ Meydanli*, ${ }^{5} \mathrm{G}$ Boyraz, ${ }^{6} \mathrm{~A}$ Ozdemir, ${ }^{7} \mathrm{H}$ Şahin, ${ }^{8} \mathrm{~T}$ Şenol, ${ }^{9} \mathrm{~N}$ Yildirim, ${ }^{5} \mathrm{~T}$ Turan, ${ }^{10} \mathrm{~T}$ Oge, ${ }^{11} \mathrm{M}$ Gokcu, ${ }^{12} \mathrm{~S}$ Taşkın, ${ }^{7} \mathrm{~A}$ Ayhan, ${ }^{2} \mathrm{~B}$ Ataseven. ${ }^{1}$ Mugla Sıtkı Kocman University, Muğla, Turkey; ${ }^{2}$ Charité University Hospital, Berlin, Germany; ${ }^{3}$ Tepecik Edication and Research Hospital, Turkey; ${ }^{4}$ Zekai Tahir Burak Women's Health Training and Research Hospital, Ankara, Turkey; ${ }^{5}$ Etlik Zubeyde Hanim Women's Health Training and Research Hospital, Turkey; ${ }^{6}$ Dr Sadi Konuk Training and Research Hospital, Turkey; ${ }^{7}$ Baskent University, Turkey; ${ }^{8}$ Zenyep Kamil Women's Health Education and Research Hospital, Turkey; ${ }^{9}$ Ege University, Turkey; ${ }^{10}$ Eskişehir Osman Gazi University, Turkey; "1'izmir University of Economics Medicine Faculty Medical Park Hospital, Gynecological Oncology, Izmir, Turkey; ${ }^{12}$ Ankara University, Turkey

10.1136/ijgc-2021-ESGO.211
Introduction/Background* The clinicopathologic characteristics, recurrence patterns, and survival of patients with grade III endometrial cancer (G3EC) and uterine carcinosarcoma (UCS) were compared.

Methodology The medical records of patients treated for G3EC and UCS between January 1996 and December 2016 at $\mathrm{X}$ gynecologic oncology centers in Turkey and Germany were analyzed.

Result(s)* UCS was diagnosed in 353 (48.2\%) of the enrolled patients and G3EC in 380 (51.8\%). The patients in each group were divided into three subgroups depending on the disease stage: early (stage IA), locally advanced (IB-II) and advanced (III-IV). For all stages, the recurrence rate was higher in patients with UCS than in those with G3EC. Adjuvant treatment type had no significant effect on disease-free survival (DFS) or overall survival (OS) in patients with early stage tumors. In patients with locally advanced disease, radiotherapy (RT) + chemotherapy (CT) was the most effective type of adjuvant therapy with respect to DFS and OS. In those with advanced disease, RT + CT was the most effective type of adjuvant therapy but only with respect to DFS.

Conclusion* The recurrence rate was higher in UCS patients than in G3EC patients, regardless of disease stage. DFS was of shorter duration in UCS than in G3EC patients. OS did not significantly differ between UCS and G3EC patients with early or locally advanced disease. In patients with early stage UCS or G3EC, adjuvant therapy modalities had no effect on survival. However, in both groups of patients with locally advanced disease, adjuvant CT and RT resulted in a significant improvement in DFS and OS.

\section{PROGNOSTIC FACTORS AND SURVIVAL OUTCOMES OF WOMEN WITH UTERINE LEIOMYOSARCOMA: A TURKISH UTERINE SARCOMA GROUP STUDY-003}

${ }^{1} \mathrm{~A}$ Ayhan, ${ }^{2} \mathrm{~K}$ Güngördük, ${ }^{3} \mathrm{G}$ Khatib, ${ }^{4} \mathrm{Z}$ Cüylan, ${ }^{5} \mathrm{~N}$ Boran, ${ }^{6} \mathrm{M}$ Gokcu, ${ }^{7} \mathrm{H}$ Celik, ${ }^{8} \mathrm{~N}$ Ozgul, ${ }^{9} \mathrm{O}$ Akbayır, ${ }^{10} \mathrm{~T}$ Simsek, ${ }^{11} \mathrm{~A}$ Bakay, ${ }^{12} \mathrm{~F}$ Köse, ${ }^{1} \mathrm{M}$ Tunç, ${ }^{3} \mathrm{U}$ Küçükgöz, ${ }^{5} \mathrm{~S}$ Koç, ${ }^{1} \mathrm{E}$ Kuscu, ${ }^{3} \mathrm{MA}$ Vardar, ${ }^{1} \mathrm{H}$ AkIll,,${ }^{13} \mathrm{C}$ Taskiran, ${ }^{14} \mathrm{MM}$ Meydanli*. ${ }^{1}$ Baskent University, Turkey; ${ }^{2}$ Mugla Sıtkı Kocman University, Turkey; ${ }^{3}$ Çukurova University; ${ }^{4}$ Ankara City Hospital; ${ }^{5}$ Etlik Zubeyde Hanim Women's Health Training and Research Hospital; ${ }^{6}$ izmir University of Economics Medicine Faculty Medical Park Hospital, Gynecological Oncology, Izmir, Turkey; ${ }^{7}$ Başkent Üniversitesi Adana Uyg. ve Araşt. Merkezi Yüreğir Başkent Hastanesi, Turkey; ${ }^{8}$ Hacettepe University; ${ }^{9}$ Kanuni Sultan Süleyman Education and Research Hospital; ${ }^{10}$ Akdeniz University; ${ }^{11}$ Ondokuz Mayıs University; ${ }^{12}$ Acıbadem University; ${ }^{13}$ Koç University; ${ }^{14}$ Zekai Tahir Burak Women's Health Training and Research Hospital, Turkey

\subsection{6/ijgc-2021-ESGO.212}

Introduction/Background* To assess the clinicopathological features, prognostic factors, and survival rates associated with uterine leiomyosarcoma (uLMS).

Methodology Databases from 15 participating gynecological oncology centers in Turkey were searched retrospectively for women who had been treated for stage I-IV uLMS between 1996 and 2018.

Result(s)* Of 302 consecutive women with uLMS, there were 234 patients with Federation of Gynecology and Obstetrics (FIGO) stage I disease and 68 with FIGO stage II-IV disease. All patients underwent total hysterectomy. Lymphadenectomy was performed in $161(54.5 \%)$ cases. A total of 195 patients received adjuvant treatment. The 5-year disease-free survival (DFS) and overall survival (OS) rates were $42 \%$ and 54\%, respectively. Presence of lymphovascular space invasion (LVSI), higher degree of nuclear atypia, and absence of 